\title{
Preliminary study of variable rate application - organic liquid fertilizer by using SPAD chlorophyll meter on System of Rice Intensification (SRI) cultivation
}

\begin{abstract}
Knowing actual nutrient requirements for rice plants is crucial in supplying the correct amount of fertilizer, especially nitrogen since nitrogen is one of the most key limiting nutrients in rice cultivation. A preliminary study of variable rate application (VRA) on System of Rice Intensification (SRI) planting by using organic foliar fertilizer was carried out to determine the effectiveness of precision fertilization. Foliar fertilizer was formulated based on actual nitrogen needed by rice plants using Soil-Plant Analyses Development (SPAD) chlorophyll meter measurements. The experiment was laid out in a randomized complete block design (RCBD) with four treatments (50\% fixed rate, $100 \%$ fixed rate, $150 \%$ fixed rate and VRA) and four replications for each treatment. Plant growth performances (plant heights, number of tillers, number of panicle and flower) and yield performances (grain yield, number of grain, 1000-grain weight and number of spikelets) were recorded during the study. The results showed that foliar application of VRA resulted in significantly higher yield performances; grain yield (13.65 g), number of grain (807.50), 1000-grain weight (16.79 g), and number of spikelets (7.50) compared to uniform fertilizer applications. VRA treatments had the highest SPAD readings at every planting stage during the experiment; however, a high nitrogen supply was needed during the mid-tillering stages (35 DAT) compared to other fertilizer rates. Besides, VRA application shows the most savings in term of total nitrogen supply $(415 \mu \mathrm{g})$ compared to uniform rates application; 50\% fixed rate (400 $\mu \mathrm{g}), 100 \%$ fixed rate $(810 \mu \mathrm{g})$, and $150 \%$ fixed rate $(1210 \mu \mathrm{g})$.
\end{abstract}

Keyword: Organic foliar fertilizer; Nitrogen supply; Growth performance; Yield performance; Precision fertilization 